\title{
The Role of TRP Channels in Migraine
}

\author{
Gerry Stephen Oxford ${ }^{1}$ and Joyce Harts Hurley*,2
}

${ }^{1}$ Department of Pharmacology and Toxicology, and ${ }^{2}$ Department of Biochemistry and Molecular Biology, Stark Neurosciences Research Institute, Indiana University School of Medicine, Indianapolis, IN 46202

\begin{abstract}
TRP channels are members of a large family of non-selective cation channels. The family which numbers over 30 is classified into 6 groups based on amino acid sequence homology. TRP channels are distributed in many peripheral tissues as well as central and peripheral nervous system. These channels are important in sensing a wide range of chemical and physical stimuli. Several TRP channels, including TRPV1 and TRPA1 are important in pain transduction pathways. This review will focus on the function of TRP channels in the trigeminovascular system and other anatomical regions which are relevant to migraine. We will discuss the possible role of TRP channels in migraine, including the potential role of TRPV1 in the hypersensitivity and allodynia frequently observed in migraine patients. We will review the status of TRP channel drugs in migraine therapeutics. We will also discuss the possible roles of TRP channels in triggering migraine attacks, a process which is not well-understood.
\end{abstract}

Kewords: Migraine, trigeminal, TRP receptor, pain, neurogenic, inflammation.

\section{INTRODUCTION}

Migraine is a common and debilitating episodic disorder characterized by unilateral throbbing headache, phonophobia, photophobia and nausea. It is sometimes preceded by aura or premonitory symptoms [1,2]. Migraine is more common in women $(18 \%)$ than in men $(6 \%)$ for reasons which are unclear $[3,4]$. The pain of migraine is connected with activation of the trigeminovascular system, comprised of the sensory neurons arising from the trigeminal ganglion and the cerebral blood vessels they innervate. Excitation of the trigeminovascular system is associated with neurogenic inflammation of the meninges and the release of neurotransmitters such as calcitonin gene-related peptide (CGRP), a potent vasodilator. The important role of CGRP in migraine has been realized and capitalized upon as CGRP antagonists have shown efficacy in clinical trials $[5,6]$.

Migraine is an episodic disorder and what triggers the attacks and where they are initiated is probably the least understood facet of migraine pathophysiology. Initiation of migraine episodes has been linked to a number of potential triggers [7, 8]. Environmental factors such as air pollution, odors, and temperature or weather changes may trigger migraine [9-11], but the supporting evidence is somewhat controversial and largely anecdotal. Physiological factors such as diet, hormonal milieu or stress may also be important triggers. Furthermore, migraine is co-morbid with a number of diseases and conditions, including multiple sclerosis [12, 13] and epilepsy [14] which may provide clues about how migraine is triggered. Where these putative triggers are

*Address correspondence to this author at the Department of Biochemistry and Molecular Biology, Stark Neurosciences Research Institute, Indiana University School of Medicine, 950, West Walnut Street, R2 402, Indianapolis, IN 46202; Tel: 317-278-7904; Fax: 317-278-5849;

E-mail: johurley@iupui.edu acting to initiate migraine is unclear, but both peripheral and central sites have been implicated.

Transient receptor potential (TRP) channels are a family of non-selective cation channels which are important in pain signaling pathways. In this article, we will discuss the expression and function of TRP channels in the anatomical substrates of migraine. We will examine the evidence that TRPs are important in migraine pain and associated symptoms, including hyperalgesia and allodynia. We will also examine the potential role of TRPs in triggering migraine episodes and how some of the postulated factors and triggers for migraine may provide clues as to the nature of TRP channel involvement. There are at least 30 members of the mammalian TRP family of non-selective cation channels, which are divided into 6 subfamilies, based on sequence homology. The TRP channels are gated by a diverse set of chemical, thermal, mechanical and other environmental signals. Their distribution is generally widespread and they are found in a variety of cell types where they are thought to sense and integrate a multitude of environmental signals. A number of excellent review articles provide further details on the TRP family $[15,16]$. This review will focus on the TRP channels implicated in pain pathways and those expressed in anatomical regions relevant to migraine, including the cell bodies, axons and peripheral and central terminals of trigeminal nociceptors, the trigeminal nucleus caudalis (TNC) and cerebral blood vessels. Several TRP family members, including the TRPV1 (Transient Related Potential Vanilloid Type 1), TRPV2 (Transient Related Potential Vanilloid Type 2), TRPV3 (Transient Related Potential Vanilloid Type 3) and TRPV4 (Transient Related Potential Vanilloid Type 4), TRPM8 (Transient Related Potential Metastatin Type 8) and TRPA1 (Transient Related Potential Ankyrin Type 1) channels, are expressed in pain sensing neurons where they detect 
temperature, physical and/or chemical signals. We will also explore the function of TRP channels in regions which may be important in headache pain initiation or processing [17].

\section{TRPV1}

The physiological roles and endogenous activators of TRP channels in sensory neurons are not well-understood, but a large part of what we know comes from studies of TRPV1. TRPV1 is considered the prototypic TRP channel as it was the first mammalian TRP channel cloned and is the most studied to date. The TRPV1 channel, previously known as the VR1 receptor, was identified through an expression cloning strategy on the basis of its sensitivity to capsaicin [18], the pungent ingredient in chili peppers. The initial descriptions of the selective actions of capsaicin on the sensory neuron subpopulation termed nociceptors precipitated the search for its receptor, a discovery which has significantly advanced our understanding of pain.

Activation of the TRPV1 channel by capsaicin, noxious heat $\left(>43^{\circ} \mathrm{C}\right)$ and protons in vivo results in a painful burning sensation. Activation of these channels is excitatory due to cation influx, primarily sodium and calcium, and the subsequent depolarization leads to activation of voltagegated calcium channels resulting in further calcium influx and neurotransmitter release. The TRPV1 receptor has been termed a "molecular integrator" $[19,20]$ as it can detect and integrate signals from a variety of noxious chemical and physical stimuli. It has been suggested that the TRPV1 ion channel acts as a "stimulus integrator" given the polymodal nature of its activation and that each of the activating stimuli is capable of potentiating the effect produced by another activator of TRPV1. The TRP channel is also activated or modulated by several endogenous ligands including anandamide, arachidonic acid metabolites and inflammatory mediators such as adenosine triphospate (ATP), bradykinin, prostaglandins and nerve growth factor (NGF) which are present in elevated concentrations during inflammation. These observations suggested a role for TRPV1 in pain perception, specifically thermal hyperalgesia during inflammation, which has been corroborated by genetic and pharmacological studies [21-23].

Structure-function studies have enumerated specific protein domains in the complex regulation of this channel $[16,24]$. TRPV1 is a six transmembrane domain protein with intracellular $\mathrm{N}$ and $\mathrm{C}$ terminals, structurally reminiscent of voltage-gated potassium channels. The sites of action of capsaicin (the intracellular loop between transmembrane domain II and III), protons (extracellular sites near pore region) and temperature sensing (intracellular $\mathrm{C}$ terminus) have been identified as well as several phosphorylation sites. The regulation of TRPV1 receptor function involves protein kinases $[25,26]$ as well as phosphatases. TRPV1 channels form homo-tetramers and, in expression systems, heterotetramers which further increases their functional diversity.

\section{TRPV1 Localization}

TRPV1 is abundantly expressed in subsets of small and medium diameter sensory neurons in dorsal root ganglion (DRG) and trigeminal ganglion (TG), which are largely unmyelinated $\mathrm{C}$ and $\mathrm{A} \delta$ fibers. In situ hybridization studies demonstrate TRPV1 message in neurons of DRG and TG
$[18,27,28]$. Immunocytochemical studies indicate that 16 to $50 \%$ of trigeminal ganglion and dorsal root ganglion cells express TRPV1 [29-32], with the variability likely attributable to species and methodological differences. Radioligand binding studies with ${ }^{3} \mathrm{H}$-resiniferatoxin, an ultrapotent agonist, have demonstrated TRPV1 receptor protein in sensory ganglia, trigeminal nucleus caudalis (TNC), olfactory nuclei, cerebral cortex, dentate gyrus, thalamus, hypothalamus, periaquaductal grey, cerebellar cortex, superior colliculus and locus coeruleus [20, 33, 34]. TRPV1 has also been reported in non-neuronal tissue including mast cells $[35,36]$, although a functional role of the channel in these cells remains questionable.

The TRPV1 receptor is highly co-expressed with calcitonin-gene related peptide (CGRP) [30-32] a potent vasodilator with an important role in migraine. TRPV1 is also co-expressed with other pain signaling molecules such as substance $\mathrm{P}$ [30], P2X3 purinergic receptors [29] and other markers of nociceptive $\mathrm{C}$ and A $\delta$ fibers. Patterns of coexpression with other TRP family members are distinct, i.e., TRPA1 is co-expressed within a subset of TRPV 1 expressing cells $[37,38]$ whereas TRPM8 is rarely colocalized with TRPV1 [37, 39, 40] but see [41].

TRPV1 is widely expressed in the anatomical substrates of migraine, particularly in soma of the trigeminal ganglion, nerve fibers, in central terminals in the TNC and in peripheral terminals within the dura [29, 30, 42, 43]. Although previous studies had demonstrated the occurrence of TRPV1 receptors in the dura, the origin of the TRPV1 protein was not known. Retrograde labeling studies have demonstrated that $25 \%$ of the trigeminal ganglion cells projecting to the dura express TRPV 1 and $80 \%$ of those express CGRP [42]. This high level of co-localization is consistent with reports that TRPV1 receptor activation in the dura stimulates CGRP release and subsequent vasodilatation [44-46]. Most studies report the presence of TRPV1 in presynaptic terminals of TNC [43, 47], but see [48]. TRPV1 has also been detected in arteriole smooth muscle in the dura [43], albeit at low abundance [49]. TRPV1 is also reported in the cochlear arterioles where it has been hypothesized to mediate inner ear disturbances in migraine $[50,51]$.

The extent and distribution of TRPV1 in the central nervous system (CNS) is the source of some debate amongst researchers. Initially the receptor was believed to be rather narrowly expressed in sensory ganglia and peripheral tissues which is consistent with its presumptive role in pain signaling. Currently, TRPV1 is thought to be more widely distributed than originally thought and it has been detected in periaqueductal grey, hypothalamus, thalamus, amygdala, cortex, olfactory bulb, trigeminal nucleus caudalis and a number of other regions of the brain in humans, rats and mice [33, 34, 47, 52, 53] but see Cavanaugh et al., [2011] [49]. Several reports have also suggested that TRPV1 is functional in the CNS in several areas including cerebral cortex [54], dentate gyrus [55], and hippocampus [56, 57].

However, conflicting reports have made it difficult to assign physiological roles for TRPV1 in the CNS and some pharmacological and genetic data appear inconsistent with important functions in these locations. For example, capsaicin failed to elicit calcium entry or neurotransmitter release from hippocampal synaptosomes [58], and vanilloids 
produced similar effects on hippocampal excitatory postsynaptic conductances (EPSC) in wildtype and TRPV1 knockout mice [59]. Furthermore most reports indicate that TRPV1 knockout mice exhibit no overt behavioral deficits [22], but some authors identified changes in behavior and/or synaptic transmission [56, 57] in mice lacking TRPV1. Finally systemic administration of capsaicin or resiniferatoxin in animals, which ablates TRPV1 expressing cells through overexcitation, reduces hyperalgesic and pain responses, but produces no other detectable behavioral changes.

Recently, Cavanaugh et al., 2011 [49, 60] using a sensitive genetic approach for lineage tracing, determined that very little TRPV1 is expressed outside of sensory ganglion except a few small regions in the CNS, notably the hypothalamus. While it is challenging to reconcile this recent data with many previous reports suggesting the existence of TRPV1 in the CNS, the specificity of biochemical tools (e.g. antibodies) and variables in their implementation may underlie the differences. In any event, this controversy is not yet resolved. The need for clarification of the CNS distribution of TRPV1 is significant with regard to the development of novel therapeutics for several conditions [61-64], including migraine. If functional TRPV1 is expressed in other regions of the CNS, this may signal additional targets to explore for drug development for other indications or likely additional side effects.

\section{TRPV1 Function}

A large body of work demonstrates that TRPV1 has an important role in pain transduction and neurogenic inflammation. TRPV1 agonists produce pain in humans and pain-like behavior in animals [24, 64, 65]. These behaviors are absent or much reduced in animals in which TRPV1 has been genetically or pharmacologically ablated [21-23]. Also, TRPV1 antagonists can block or reduce pain-like behaviors in animals. TRPV1 mRNA, protein and/or protein translocation are increased during inflammation and neuropathic pain in DRG [66, 67] and trigeminal ganglia [68]. In some cases where it has been examined, the increased expression of TRPV1 is primarily in A $\delta$ fibers [67, 69]. In rats, turpentine injection into the facial area transiently decreased head withdrawal latency to both heat and cold and increased the number of TRPV1 expressing cells, as well as TRPV1 staining in the peripheral (vibrissal) and central terminals in TNC [68]. These specific changes in TRPV1 expression underlie the importance of TRPV1 in hyperalgesia associated with inflammation or tissue damage.

TRPV1 is present in peripheral and central nerve terminals $[43,47]$ of trigeminal ganglion neurons where it mediates neurotransmitter release. Capsaicin stimulates release of CGRP from dural tissue [70] and TRPV1 activation of peripheral nerve terminals in the dura induces CGRP-dependent vasodilatation [44-46] which can be blocked by capsezepine, a TRPV1 antagonist [71]. This suggests that TRPV1 may have a role in the initiation and propagation of migraine and its accompanying hyperalgesia and allodynia [72]. It was proposed that TRPV1 receptors are important mediators of CGRP and substance P release from peripheral nerve terminals. CGRP and substance $P$ induce vasodilatation and plasma extravasation in the meninges. This is accompanied by the release of inflammatory mediators and mast cell degranulation and the resulting inflammatory soup sensitizes trigeminal nociceptors [73]. Sensitizing agents, such as bradykinin, PGE2 $[74,75]$, ATP and NGF all have excitatory actions on nociceptors and are all known to converge through different signaling pathways to modulate TRPV1. TRPV1 channel function is potentiated by these agents via phosphorylation, increased membrane trafficking and increased expression. TRP channel sensitization may contribute to the peripheral and central sensitization which underlies hyperalgesia and allodynia seen in a large percentage of patients. In support of this theory, NGF produces hyperalgesia in animals and humans and is elevated in cerebral spinal fluid in chronic migraine sufferers [76].

TRPV1 is present in other peripheral tissues where it may have a role in migraine symptoms. Inner ear disturbances including phonophobia, tinnitus, fluctuations in hearing perception and increased noise sensitivity are often seen during attacks. The trigeminal ganglion innervates the cochlea [77] and capsaicin stimulates blood flow and neurogenic inflammation in the inner ear [50]. This observation and the subsequent report that TRPV1 and substance $\mathrm{P}$ are co-localized in nerve fibers (presumably of trigeminal origin) surrounding cochlear arterioles [51] prompted the suggestion that TRPV1 may mediate inner ear perturbation during migraine. Another study has suggested that the tinnitus, which worsens in intensity during migraine in some patients, may be a form of allodynia related to abnormal cortical function [78].

While it is clear that TRPV1 has an important function in pain signaling in the peripheral nervous system, its role in the CNS is less clear. TRPV1 receptors in the CNS may subserve important roles in synaptic transmission and plasticity [56, 57] and have been implicated in anxiety, glucose metabolism and temperature regulation [56, 79]. These reports are not all in agreement and the existence and role of TRPV1 channels in the central nervous system is still under debate [49]. However, the possibilities are intriguing as some areas where TRPV1 is postulated to be important are also implicated in migraine susceptibility, including the PAG, hypothalamus, thalamus and cortex $[33,34,52,53]$.

\section{TRPV1 Therapeutics}

As reviewed elsewhere [24, 61, 62, 64, 65], TRPV1 ligands are considered to have significant potential as therapeutics for a variety of chronic pain conditions, including cancer, osteoarthritis, neuropathy and migraine. Although TRPV1 receptors are being targeted for a number of conditions we will focus on clinical trials of migraine and cluster headache. Cluster headache shares some pathophysiological characteristics of migraine including involvement of the trigeminovascular system [80].

Compared to other targets, TRPV1 receptors are unusual in that both agonists and antagonists are considered good prospects for drug discovery efforts. TRPV1 agonists are predicted to be efficacious because they produce significant and long lasting desensitization of capsaicin-sensitive pain transducing neurons and relieve pain-like behavior in animals and pain in humans. Alternatively, TRPV 1 antagonists are viewed as therapeutic leads because TRPV1 agonists themselves cause pain, TRPV1 is up-regulated in 
inflammation and other painful conditions and thermal hyperalgesia after inflammation is attenuated in TRPV1 knock-out mice [21, 22]. Antagonists, which presumably block the actions of endogenous ligands and/or sensitized thermal responses of TRPV1, have been shown to relieve pain in inflammation, cancer and osteoarthritis $[64,65]$.

An unusual characteristic of TRPV1 agonists such as capsaicin, civamide and resiniferatoxin is their ability to produce a long lasting refractory state to many diverse stimuli in sensory neurons after the initial excitation [20]. This characteristic has been studied in animals and is now being taken into the clinic. In fact, this property of capsaicin has been used for many years in over the counter preparations to relieve joint and muscular pain. Pre-clinical studies have demonstrated that a single administration of resiniferatoxin $[63,81,82]$ can produce profound and long lasting effects on pain perception. The mechanism of this nociceptive desensitization is debated but may include neuronal defunctionalization or ablation [65]. Animal studies have demonstrated that capsaicin, civamide and resiniferatoxin decrease TRPV1 receptor message and protein and deplete neurotransmitters including CGRP and Substance $\mathrm{P}$ from sensory neurons, thus attenuating pain-like behavior in animals. Unfortunately, the agonists used in these studies are not amenable to systemic administration as they perturb blood pressure and heart rate and most efforts are now being directed toward local administration.

Clinical trials of capsaicin and civamide for migraine or cluster headache are ongoing and some have been completed. These studies have focused on nasal administration of capsaicin and its analogs. Intranasal capsaicin or civamide, a stereoisomer of capsaicin, have shown some benefit in episodic migraine [83, 84] and chronic migraine [85]. Marks and colleagues [86] conducted a double blind placebo controlled trial of capsaicin for cluster headache and reported a significant decrease in headache severity after 8 days compared to placebo. Additional trials of capsaicin [87] and civamide [88] have also reported efficacy in cluster headache. Two trials of civamide in cluster headache are complete, but have not been reported as of yet (http://www.clinicaltrials.gov identifier: NCT00069082, NCT00033839). Due to the mode of action of TRPV1 agonists, i.e. desensitization of capsaicin-sensitive nociceptors, some authors suggest that these agents are better suited for prophylactic treatment of chronic headache [83, 89]. The results of ongoing or not yet reported studies may clarify this issue. Nasal administration is predicted to have some advantages over oral or topical administration as lower dosages may be used and the absorption is fast [90]. However, from a practical standpoint, the initial burning, lacrimation and rhinorrhea produced by nasal administration of TRPV1 agonists likely deters some patients. As this side effect decreases with repeated dosing and several trials have reported efficacy, nasal administration of TRPV1 agonists is still being actively pursued clinically. Topical administration at peripheral sites is being tested. Topical application of capsaicin jelly on painful scalp arteries has been tested with modest success [91] and hopefully future studies will assess more potent compounds.

Other TRPV1 antagonists are being extensively pursued for drug development. TRPV1 antagonists relieve pain-like behavior in inflammation, cancer and osteoarthritis in animals and some clinical trials have demonstrated efficacy (see Wong and Gavva (2009) [64] and references therein). The mode of action of TRPV1 antagonists varies, but is presumed to functionally block endogenous TRPV1 agonists or enhanced spontaneous TRPV1 activity which occurs during inflammation and tissue damage.

Preclinical studies of TRPV1 antagonists in animal models of migraine $[92,93]$ have been elucidating. Systemic administration of SB 705498 in cats reversed and prevented sensitization of TNC responses by inflammatory soup to electrical or mechanical stimulation of dura or facial skin [92]. The authors hypothesized that SB 705498 may block central sensitization and based on this and pharmacokinetic arguments suggested that SB 705498 may be better suited for treating the allodynia seen in transformed migraine. In contrast, the potential of TRPV1 antagonists for acute migraine has been called into question by another animal study. Goadsby and colleagues [93] examined the effect of the TRPV1 antagonist, A-993610, on in vivo models of migraine. In their study, A-993610 did not block enhanced nerve activity in the trigeminocervical nuclear complex induced by electrical stimulation of the middle meningeal artery, had no effect on neurogenic dural vasodilatation, but blocked capsaicin induced vasodilatation. Furthermore A993610 did not block mechanically induced cortical spreading depression. These results suggest TRPV1 may not be an effective target for acute migraine therapy.

However, a most surprising report by Evans et al. (2012) [43] may reinvigorate interest in TRPV1 antagonists as acute migraine therapeutics. This recent paper suggests that sumatriptan, the prototypic 5HT1 agonist used in migraine, is a TRPV1 antagonist. In this study, sumatriptan inhibited capsaicin induced currents in dissociated trigeminal ganglion neurons and increased EPSPs in trigeminal nucleus neurons in brain stem slices. Another point of interest in this story is the report that triptans can be used to treat allodynia [94, 95] (although see Burstein et al, (2000) [96]). These results together suggest a pivotal role for TRPV1 in trigeminovascular pain and its central transmission.

While early reports were promising, initial excitement about clinical trials with several TRPV1 antagonists has diminished due to untoward side effects. Reports of hyperthermia and profoundly impaired perception of noxious heat stimuli in patients or healthy volunteers have appeared (as reviewed by Eid (2011) and references therein [61] ). In some cases the hyperthermic effect appears to diminish after repeated administration in humans as it does in some animal studies. Several additional studies of TRPV1 antagonists are ongoing and some completed, but the results have not been reported.

A research area which may contribute to the identification of TRPV1 antagonists without the effects of body temperature and loss of heat perception are efforts to classify antagonists based on their ability to modulate distinct forms of TRPV1 activation such as those initiated by capsaicin, protons or temperature elevation [64]. At the present no separate activation-dependent efficacies have been found that might mitigate body-temperature responses, however this line of study should lead to a better understanding of the mechanisms involved in both. 


\section{TRPA1}

TRPA1 is a non-selective cation channel of the transient receptor superfamily. The TRPA1 receptor, formerly known as ANKTM1, was originally cloned and described as a noxious cold sensing receptor [37]. TRPA1 expression, pharmacology and function are discussed in several reviews [97, 98]. TRPA 1 is activated by a variety of pungent chemicals from plants, including cinnamaldehyde [99], allicin, and diallyl disulfide (in garlic) [38,100], isothiocyanates (in mustard oil, wasabi, horseradish) [99, 101] and umbrellulone $[102,103]$, the active agent from the 'headache tree'.

TRPA1 detects environmental irritants such as acrolein [104], formaldehyde [105] and toluene [106]. Acrolein is found in cigarette smoke, tear gas and is also a metabolite of some chemotherapeutics. TRPA 1 is activated by endogenous products of inflammation and oxidative stress, including 4hydroxynonenal $[107,108]$ and 15-deoxy- 12,14prostaglandin $\mathrm{J} 2\left(15 \mathrm{dPGJ}_{2}\right)$ [109], as well as by intracellular protons [110, 111], acetaldehyde [112], $\mathrm{H}_{2} \mathrm{O}_{2}$ [108], $\mathrm{CO}_{2}$ [110] and anesthetics such as isoflurane [113]. TRPA1 can also be modulated by inflammatory mediators including bradykinin [99] and NGF [114] through undefined signaling mechanisms. With advancing study the list of known activators and modulators of TRPA1 keeps increasing.

TRPA1 activation by various agonists occurs through a rather unusual mechanism for a membrane receptor, namely covalent modification of intracellular amino acids, rather than a classical lock-and-key mechanism. It was noted that many of the diverse set of chemicals capable of stimulating TRPA1 were reactive electrophiles $[115,116]$. Both groups demonstrated that compounds such as allyl isothiocyanate and cinnamaldehyde form covalent interactions with cysteine residues in the intracellular $\mathrm{N}$ terminus of the channel. The fate of the receptors following covalent modification is unclear as well as how mechanisms of desensitization or sensitization may differ under these conditions. However, somewhat analogous to TRPV1, sensitization of TRPA1 responses by phosphorylation and membrane trafficking has been described [117].

\section{TRPA1 Localization}

TRPA1 is selectively expressed in a subpopulation of TRPV1 expressing neurons in the dorsal root ganglia, trigeminal, and nodose ganglia [37, 101], as well as in hair cells of the inner ear $[118,119]$. In situ hybridization studies are in good agreement with mouse [120] and rat [40] showing similar expression populations in the trigeminal ganglion ( $36.5 \%$ and $36.7 \%$, respectively), while $20 \%$ was reported in neonatal rat [101]. TRPA1 is also co-expressed with CGRP and markers of $\mathrm{C}$ fibers [38, 40, 120]. Immunocytochemistry identifies TRPA1 proteins in both cell bodies and sensory nerve fibers [120, 38]. Functional TRPA1 responses are present in peripheral and central terminals of nociceptors [121].

\section{TRPA1 Function}

TRPA1 agonists produce pain-like behavior in animals $[99,105]$ and pain in humans. TRPA1 antagonists or genetic deletion of TRPA1 provides further evidence for the importance of TRPA1 in pain pathways. Sensory neurons from TRPA1 knock-out mice do not respond to mustard oil or allicin [104], nor can bradykinin induce hyperalgesia in TRPA1 -/- mice. TRPA1 was implicated in the detection of noxious cold, however this role is in dispute and remains unresolved despite the efforts of many researchers [122, 123]. It may be that like TRPV1, TRPA1 has a more important role in inflammation-induced hyperalgesia than in acute temperature sensation. For example, cold hyperalgesia can be induced in wildtype mice but not in TRPA1 knockout mice [124]. A selective TRPA1 antagonist, HC-030031 $[105,125]$ reduces cold hyperalgesia associated with inflammation or neuropathic pain. Del Camino et al. [124] also observed that noxious cold temperatures had little effect on TRPA1 currents whereas slight cooling dramatically increased agonist induced currents. Therefore, it is likely that TRPA1 contributes to cold hypersensitivity, but may not have a significant role in detecting acute cold sensation.

In the trigeminovascular system, TRPA1 agonists induce CGRP release from trigeminal neurons [126] and dural tissue [103] and stimulate meningeal vasodilatation [103, 126]. Studies on the potential role of TRPA1 in migraine are just beginning. TRPA1, as an environmental irritant detector, has been strongly implicated in asthma, respiratory disorders, allergy and other conditions [127-129]. In these disorders, the first exposure to irritants is in the nasal mucosa and respiratory passages. Nasal administration of TRPA1 agonists and irritants induces meningeal vasodilatation which is TRPA1 and CGRP receptor dependent $[103,126]$. We have proposed a mechanism for air-pollution induced headache via activation of TRPA1 receptors at trigeminal nerve terminals in the nasal mucosa and subsequent activation of the trigeminovascular system. Future studies will delineate the mechanisms involved and may aid in the increased understanding of air pollution-induced headache and other health problems, a growing issue world-wide.

\section{TRPA1 Pharmacology}

The pharmacology of TRPA1 is complex. There appears to be significant species differences in responses (for examples see Chen et al. (2008) [130]. In addition, despite low sequence homology between TRPA1 and other TRP family members, some ligands cross react between members. For example, the well-known TRPM8 agonist menthol has a bimodal effect; activating TRPA1 at low concentrations and inhibiting at high concentrations [131, 132]. Mustard oil, the prototypic TRPA1 ligand also has a concentration dependent effect, activating TRPA1 at low concentrations and inhibiting at high concentrations. Furthermore, mustard oil has also been reported to activate TRPV1 though with lower potency [133]. TRPA1 antagonists have been developed $[125,134,135]$ and are being pursued as therapeutics.

\section{TRPA1 Interactions}

The characteristics and expression patterns of TRPA1 parallel those of TRPV1 in many ways and in fact their function and regulation is tightly intertwined. They both detect pungent plant compounds. They are both modulated by temperature and components of the inflammatory milieu. They are co-expressed in nociceptive neurons where they trigger or enhance neurotransmitter release, and both are upregulated with pain and inflammation [66-69, 114, 136, 137]. There is a growing body of work which demonstrates 
their functional and physical interaction [138]. The intricate pharmacology and functional interactions between TRPA1 and TRPV1 are just beginning to be understood. Exploring their interactions may gain us insight into their roles in migraine and other painful conditions and help in drug discovery efforts as well.

\section{TRPA1 Therapeutics}

TRPA1 antagonists are being developed for therapeutics for several painful conditions $[61,62]$, supported by various pre-clinical studies. Genetic ablation [104] or knockdown $[136,139]$ of TRPA1 attenuates in vivo responses to irritants. TRPA1 expression levels have been shown to increase with inflammation and tissue injury [136]. Furthermore, the hyperalgesia induced by inflammation and injury can be blocked by TRPA1 antagonists $[134,135]$. There is some optimism in the development of TRPA1 antagonists as therapeutics as the restricted localization of TRPA1 compared to TRPV1 may be an advantage and more importantly no body temperature changes have yet been reported. However, TRPA1 has not been a primary target for migraine therapeutics as of yet.

\section{Other TRP Channels}

Over 30 members of the mammalian TRP channel family have been identified (for reviews see $[15,16]$. In addition to TRPV1 and TRPA1 described above, there are several more which could be involved in migraine. Three other members of the Vanilloid subfamily, TRPV2, TRPV3 and TRPV4 and one member of the Melastatin family, TRPM8 are expressed in tissues relevant to migraine or have been implicated in pain pathways. Sensory neurons express multiple types of TRP channel members, some of which have overlapping function and significant sequence homology. In addition, some TRP family members have splice variants and can form heterotetramers further increasing the potential for functional diversity. Because of these characteristics and a general lack of specific pharmacological agents and/or antibodies it has been difficult to delineate their functions, distributions, and in vivo activators.

\section{TRPV Family}

In addition to TRPV1, other gene products including TRPV2, TRPV3 and TRPV4 have been identified in trigeminal neurons as well as a diverse set of brain and peripheral tissues. Similar to TRPV1, TRPV2 - 4 have putative roles as thermosensors [140]. TRPV2 was initially implicated in sensing noxious heat $\left(>52^{\circ} \mathrm{C}\right)$. However this has been questioned recently as TRPV2 knock-out mice do not exhibit defects in thermal hyperalgesia or mechanical allodynia [141]. TRPV3 [142] is expressed in trigeminal ganglia and a variety of other tissues and is activated at temperatures above $40^{\circ} \mathrm{C}$. It has been widely studied for its importance in neuropathic pain and several TRPV3 antagonists are in pre-clinical or early clinical trials for chronic neuropathic pain. In contrast, no specific evidence has yet appeared that either is TRPV2 or TRPV3 is important in migraine.

TRPV4 has been identified as a probable thermosensor, mechanosensor and osmosensor. It is expressed in a variety of tissues including trigeminal ganglia, where TRPV4 may contribute to some migraine symptoms. Dural afferents are activated by mechanical stimulation [143] and it was hypothesized that activation or sensitization of these afferents may be the source of throbbing head pain seen in migraine after movement or coughing. TRPV4 receptors in trigeminal afferents are considered a candidate for this role and deficits in mechanical sensing observed in TRPV4 knock-out mice [144] lend support to this hypothesis. A recent study has provided further evidence for a role of TRPV4 in migraine. The study of Wei and colleagues (2011) [145] demonstrated that activation of TRPV4 on dural afferents produces headache related behavior in a rat model of migraine. In this study retrograde labeling was used to identify dural afferents and approximately $50 \%$ of them were sensitive to hypotonic solutions or $4 \alpha$-PDD, both known activators of TRPV4. Topical application of these ligands to the dura produced allodynia which could be blocked by a TRPV4 antagonist in vivo. Consequently, it is likely that TRPV4 antagonists will be further evaluated as a possible therapeutic in migraine, just as they are currently being evaluated for neuropathic pain [146].

\section{TRPM8}

TRPM8 is classified as a cold and menthol receptor [39, 147] and is expressed in a variety of tissues including trigeminal sensory neurons. It is expressed in small-diameter primary sensory neurons, but co-localization studies are not in agreement as some report co-expression with other nociceptive markers (TRPV1 and CGRP) while others do not (for more references, see Knowlton and McKemy (2011) [148]. TRPM8 appears to be more highly expressed in trigeminal ganglia than dorsal root ganglia [40] and within trigeminal ganglia it is more abundant in the region of mandibular branch input. TRPM8 knock-out mice exhibit significant deficiencies in behavioral responses to a range of cold temperatures [149-151]. Both TRPM8 and TRPA1 receptors have been considered putative cold detectors, but their relative importance is still debated [122, 123]. From the present evidence, it appears that TRPM8 may be more important in detecting environmental cold and TRPA1 in cold hyperalgesia $[62,123]$. TRPM8 appears to be a key mediator in neuropathic and inflammatory pain [152] and is a target of therapeutic development in the treatment of several painful conditions. For example, TRPM8 receptor activation has been implicated in the neuropathy produced by the chemotherapy agent, oxaliplatin [153]. TRPM8 exhibits a similar paradoxical feature to TRPV1 in the potential use of either agonists or antagonists in drug design, as over the counter menthol patches are available for migraine and other pain relief. However, no clinical trials for TRPM8 agonists or antagonists in migraine have been reported.

In summary, our understanding of the physiological roles and therapeutic potential of TRP channels is advancing rapidly, but whether TRP channels will be efficacious targets for migraine remains to be seen.

\section{TRP Channels and Migraine Triggers}

The precise involvement of physiological or environmental triggers in initiating migraine is not wellunderstood, but approximately 75\% [7] of migraineurs report that specific triggers are linked to their migraine episodes. The most commonly reported migraine triggers are stress, 
hormones, not eating, weather, sleep disturbance, perfume or odor, neck pain, lights, alcohol or smoke [7-10, 154]. How these divergent triggers might initiate migraine is unclear and whether the origin of migraine pain is anatomically central or peripheral is highly debated. There are many excellent reviews on this subject [155-162]. Here, we will discuss some specific examples of how and where intrinsic or extrinsic factors may modulate TRP channel function and promote (initiate or exacerbate) migraine headaches.

Generally, the hypotheses about the site of migraine initiation fall into two categories. One theory advocates the importance of central structures, while the other theory suggests that migraine is initiated by activation of peripheral substrates, i.e., meningeal afferents. Central nervous system structures implicated include cortical or subcortical areas [156]. Although the existence and importance of TRPV1 channels in the CNS is debated [33, 60,60], we will presume that the evidence indicating TRPV1 has multiple roles in the CNS is valid for the purpose of this discussion.

Some subcortical and limbic areas are hypothesized to be important in migraine with support coming from clinical and imaging studies $[163,164]$. In particular, the periaqueductal grey has been termed a 'migraine generator' [165], but the available evidence is not conclusive. A more recent hypothesis suggests a mechanism where multiple triggers act on different structures to activate a common pathway of parasympathetic activation of the trigeminovascular system [156]. Specifically, many common migraine triggers activate subcortical structures including the lateral hypothalamus (food and sleep deprivation), periaqueductal gray, bed nucleus of stria terminalis and periventricular nucleus of hypothalamus (stress) and piriform cortex (olfactory stimuli). Each of these areas, as well as others, provides input to the superior salivatory nucleus and the parasympathetic sphenopalatine ganglion, which when stimulated results in meningeal vasodilation and activation of trigeminal afferents. TRPV1 is postulated to have important functions in some of these sites [53, 166] and could be involved in central migraine triggering, but no experimental evidence in support of this hypothesis has been reported.

Evidence for cortical initiation is generally based on theories of hyperexcitability of the cortex in migraine [163, $164,167]$ and studies of cortical spreading depression [155, 168] and references therein), the electrophysiological correlate of aura. Several lines of evidence support the likelihood of cortical hyperexcitabilty in migraine, including imaging studies in patients (as reviewed by Welch (2005) [164], the effects of genetic mutations in familial types of migraine $[169,170]$ and an association with epilepsy [14, 164]. For example, cortical hyperexcitability is associated with epilepsy, another episodic disorder co-morbid with migraine [14). In this regard, anti-epilepsy drugs are reported as effective in migraine prophylaxis [164, 171], and they reduce susceptibility to cortical spreading depression in animal studies. Thus, it is hypothesized that general hyperexcitability in combination with other factors may trigger migraine.

If cortical hyperexcitability has a role in initiation of migraine then it is reasonable to ask whether expression and function of TRP channels in the cortex might be important in the pathogenesis of migraine. A recent report suggests that TRPV1 regulates cortical excitability [54]. This study describes a SNP allele in the TRPV1 channel which is associated with enhanced synaptic transmission in the cerebral cortex. The channel coded by this allele also produces larger currents in heterologous expression studies [172]. Subjects were assessed with transcranial magnetic stimulation using a paired pulse stimulus in motor cortex. Subjects homozygous for this allele exhibited larger shortinterval intracortical facilitation, a measure of glutamate transmission. Approximately $6 \%$ of the healthy volunteers recruited for this study were homozygous for this allelic variant. It would be potentially fruitful if future studies include examining the allelic distribution in migraine patients and the properties of this channel variant in sensory neurons.

Cortical hyperexcitabilty increases susceptibility to spreading depression in animal models of migraine [173175]. Cortical spreading depression (CSD) is the phenomenon where a slow wave of transient excitation followed by a sustained depression of electrical activity moves across the cortex. Cortical spreading depression in the occipital cortex is believed to be the source of visual aura seen in some migraine patients. It has been demonstrated that cortical spreading depression activates the trigeminovascular system $[155,168,176-178]$ to induce excitability of trigeminal and trigeminal nucleus caudalis neurons, meningeal vasodilatation, plasma protein extravasation and increased c-fos expression in the trigeminal nucleus caudalis. It is postulated that CSD can initiate migraine pain, but how trigeminal afferents are activated as a consequence of CSD is not clear. The excitation of cortical neurons results in high concentrations of protons, glutamate, $\mathrm{K}^{+}$and ATP which presumably cross the subarachnoid space to activate pial and meningeal afferents likely through axon reflex. TRP channels are a possible candidate for activation of trigeminal afferents after CSD as TRPV1 is activated by protons.

In support of the peripheral initiation theory, a large body of evidence suggests that the origin of migraine pain may arise from inflammation of the meninges and subsequent activation of meningeal nociceptors [73, 179, 180]. The supporting evidence includes the elevated levels of inflammatory mediators observed during migraine attacks $[76,181,182]$, the therapeutic efficacy of non-steroidal antiinflammatory drugs, and mast cell involvement [180,183]. Mast cell degranulation, which is thought to be induced by CSD, releases a number of inflammatory mediators that activate and sensitize intracranial nociceptors [73, 179, 180]. Some of these mediators, including bradykinin, prostaglandins, eicosanoids and NGF sensitize TRPV1 and/or TRPA1 channels and increase their activation. This indirect evidence suggests a mechanism for the initiation of migraine pain by TRP channel activation of meningeal nociceptors after CSD or local inflammation.

\section{Genetic Predisposition}

As previously reviewed [169, 170, 184], genetics contributes significantly to the expression of migraine. Over $50 \%$ of patients have at least one first degree relative with migraine. Some rare familial forms of migraine are due to single gene mutations in the Cav2.1 voltage-gated calcium channel [185], a $\mathrm{Na}^{+}, \mathrm{K}^{+}$-ATPase [186], the Nav1.1 voltage- 
gated sodium channel [187] or TRESK, a potassium channel [188]. These mutations are all predicted to increase neuronal excitability. For example, mice bearing Familial Hemiplegic Migraine (FHM) mutations in the Cav2.1 protein exhibit enhanced susceptibility to cortical spreading depression $[173,175]$, presumably due to increased release of neurotransmitters in these gain-of-function channels [169].

The single gene mutations described above are associated with rare monogenic forms of migraine, rather than common forms of migraine with or without aura. Most previous population or linkage studies have been inconclusive or difficult to replicate perhaps due to clinical heterogeneity or small sample size. However, one recent report is of note. Chasman et al., (2011) [189] used a genome-wide association study to identify SNPs linked to increased risk of migraine. They identified a SNP in close proximity to TRPM8 that is associated with a small increase in migraine risk. The TRPM8 channel detects cold temperature and mediates neuropathic pain and now is the first TRP channel genetically linked to migraine.

In contrast to SNP analysis representing proximity relationships, genetic alterations in coding regions of TRP channels have not, as of yet, been linked to migraine. However, the first TRP channel gene mutation linked to a pain syndrome has recently been described. Kremeyer and colleagues [190] have described a gain-of-function mutation in TRPA1 associated with an episodic pain syndrome. Although the report does not mention migraine or headache, the patients suffer debilitating upper body pain which is triggered by fatigue, fasting or stress, some of the most commonly reported migraine triggers [7]. In fact, cold temperature (i.e., swimming in cold water) is cited as a contributing factor to attacks which is intriguing in light of the putative role of TRPA1 in cold hyperalgesia [124].

These studies of genetic variation of TRP channels linked to migraine or other pain syndromes are exciting and future studies focusing on these mutations should increase our understanding of the functions of TRP channels and their possible roles in migraine.

\section{Environmental Factors}

Extrinsic or environmental factors such as alcohol, air pollutants and cigarette smoke are widely cited as migraine triggers, some of which have recently been identified as TRP channel agonists.

It has been known for many years that alcoholic beverages can precipitate migraine. In fact, migraine sufferers tend to consume less alcohol [191] presumably due to compensatory avoidance. A possible mechanism for alcohol-induced headache was described by Trevisani and colleagues who reported that ethanol lowers the activation temperature of TRPV1 [192]. In a later report they demonstrated that alcohol stimulates neurogenic plasma extravasation and meningeal vasodilatation [193] in a TRPV1-dependent manner after intragastric administration of the ethanol equivalent of 3-4 drinks. In addition, alcohol stimulated the release of CGRP and Substance P from dura mater. Finally, other constituents of alcoholic drinks such as sulfites have also been implicated as migraine triggers in some sensitive individuals [194].
Odors, particularly perfume, smoke and air pollution are frequently cited as migraine triggers. Headache is the most common complaint linked to indoor and outdoor air pollution. The mechanisms are not well-understood, but may be linked to TRP channels in some cases. For example, the TRPV1 channel has been implicated [195] in Multiple Chemical Sensitivity [196], an acquired disorder usually precipitated by low- level exposure to chemicals over a sustained length of time or a single high level exposure. Afterwards patients are hyper sensitive to low levels of many chemicals and suffer from headache, fatigue, respiratory and skin problems. Although no diagnostic pathology has been identified, patients have increased levels of the inflammatory mediator NGF, a TRPV1 and TRPA1 modulator [197], and heightened TRPV1 responses [198].

Little is known about air pollution induced headache, but some clues may be taken from allergy, asthma and other illnesses related to bad air quality [127, 128]. Migraineurs are more likely than the general population to have disorders such as asthma, allergy and eczema which can be triggered or worsened by allergans or irritants. Neurogenic inflammation related to chemical sensitivity is postulated to have a role in these disorders [199] and similar mechanisms may mediate air pollution induced headache. Some components of smoke and air pollution, such as acrolein and formaldehyde, activate TRPA1 channels, the environmental irritant detectors. It has been demonstrated that TRPA1 is an important mediator of neurogenic inflammation in a mouse model of asthma [128]. Also cigarette smoke causes TRPA1dependent neurogenic inflammation in the airways [200].

As several disorders, triggered or worsened by environmental irritants, seem to be linked to TRPA1 and inflammation, we hypothesize that environmental irritants may likewise initiate headache through TRPA1 receptors, activation of sensory neurons and inflammation. We have previously reported that acrolein and other irritants stimulate release of CGRP from trigeminal neurons and increase meningeal blood flow after nasal administration [126] in a TRPA1-dependent manner. In addition to environmental irritants, TRPA1 receptors are activated by pungent ingredients from plants. Ingestion of these ingredients does not promote headache, but topical administration on nasal mucosa produces burning and sometimes painful cold sensation. Anecdotal reports over many years have described a headache tree, the California bay laurel, whose vapors elicit severe headaches (see Benemei et al., 2010 [201] and earlier references therein). Recently, the active ingredient, umbrellulone has been identified which produces a painful cold sensation after topical administration and activates TRPA1 in heterologous expression systems [102, 103]. Umbrellulone increases the excitability of trigeminal neurons and stimulates CGRP release from dura, two responses not observed in TRPA1 knock-out mice. In addition, umbrellulone increases meningeal blood flow after nasal or systemic administration. This report lends support to the hypothesis of Kunkler et al. (2011) [126] that environmental irritant-induced headache is mediated by TRPA1 activation of the trigeminovascular system.

Weather, including heat, humidity and low atmospheric pressure are also frequently reported as migraine triggers, but clinical studies are few and inconclusive. As triggers, these 
factors are also difficult to understand from a mechanistic standpoint. For example, high altitude climbers are exposed to low atmospheric pressure, but studies of headache associated with altitude sickness are confounded by other triggers, including food and sleep deprivation and dehydration. Surprisingly, migraineurs do not report airplane travel as a trigger, despite the usual presence of multiple verified triggers, including low atmospheric pressure and changes in sleep, diet and alcohol consumption. Bolay and Rapoport (2011) [11] have advanced a theory correlating weather changes and migraine to the abundance of desert dust particles at particular times of the year. They demonstrated that the trigeminovascular system is activated by conditions simulating an African dust-laden atmosphere [202]. Airborne desert dust particles contain products of microbial metabolism including $\mathrm{Fe}^{2+}$, oxalate and basic amino acids. It is not clear which components of desert dust are responsible for activating the trigeminovascular system. Given the broad array of compounds that activate or modulate TRPA1 channels, they are obvious mechanistic candidates for these induced syndromes.

Stress is the most frequently reported trigger for migraine [7] and a number of other conditions which are co-morbid with migraine, including asthma, eczema and multiple sclerosis are also aggravated by stress. As mentioned above, stress in the form of sleep or food deprivation could activate sub-cortical structures and subsequently the trigeminovascular system [156]. Alternatively, stress could contribute to migraine episodes through inflammatory mechanisms, i.e., activation of meningeal immune cells. For example, mast cells in the meninges are activated after restraint stress in animals [183]. Degranulation of mast cells releases a number of inflammatory mediators which contribute to sensitization of nociceptors [73, 179]. Several mast cell mediators including bradykinin, prostaglandins and eicosanoids sensitize TRPV1 and TRPA1 channels, possibly implicating their involvement in stress induced migraine.

Acrolein, in addition to being considered an exogenous TRPA1 agonist found in smoke and air pollution, is also produced in significant amounts in some disorders associated with oxidative stress. Oxidative stress, caused by tissue damage or other pathological processes can result in accumulations of acrolein and 4-hydroxynonenal due to lipid peroxidation. Acrolein is highly reactive, has a long half-life and can diffuse some distance from the site of injury in animal models of mild traumatic brain injury [203]. As both acrolein and 4-hydroxynonenal are TRPA1 activators it is conceivable that their accumulation under these conditions may contribute to migraine susceptibility in multiple sclerosis and brain injury. For example, migraine is more prevalent in the military than in the general population (NINDS Migraine Information/NIH report) and is more likely with a history of mild head trauma [204]. The combat environment is suggested to predispose to migraine perhaps due to a combination of stress and high incidence of traumatic brain injury.

In summary, we are just beginning to understand the role of TRP channels in migraine. Whether they will play a leading or supporting role is unclear. Indirect evidence suggests that TRP channels, particularly the TRPV1 channel may be important in the activation of meningeal nociceptors after CSD or inflammatory insults. TRPV1 receptors may have a role in hypersensitivity and allodynia seen in migraine and they may be partly responsible for the efficacy of a common migraine treatment, sumatriptan. We have described several examples of how TRP channels may be involved in triggering migraine episodes. We hypothesize that a diverse set of environmental and physiological triggers converges on a common group of signal integrators, the TRP channels, to promote migraine. Many questions remain unanswered but are worth pursuing as migraine is one of the most undertreated neurological disorders.

\section{CONFLICT OF INTEREST}

The authors confirm that this article content has no conflicts of interest.

\section{ACKNOWLEDGMENTS}

We would like to thank Dr. Phillip Kunkler for a critical review of the manuscript. This work was supported by a grant from NIEHS (ES017430) to GSO and JHH. There are no personal or financial conflicts of interest in publishing these data.

\section{REFERENCES}

[1] Lipton RB, Diamond S, Reed M, Diamond ML, Stewart WF. Migraine diagnosis and treatment: results from the American Migraine Study II. Headache 2001; 41(7): 638-45.

[2] Headache classiffication subcomittee of the international Headache society. The International Classification of Headache Disorders: 2nd ed. Cephalalgia 2004; 24 (Suppl 1): 9-160.

[3] Stewart WF, Lipton RB, Celentano DD, Reed ML. Prevalence of migraine headache in the United States. Relation to age, income, race, and other sociodemographic factors. JAMA 1992; 267(1): 649.

[4] Stewart WF, Wood C, Reed ML, Roy J, Lipton RB. Cumulative lifetime migraine incidence in women and men. Cephalalgia 2008; 28(11): 1170-8.

[5] Olesen J, Diener HC, Husstedt IW, et al. Calcitonin gene-related peptide receptor antagonist BIBN $4096 \mathrm{BS}$ for the acute treatment of migraine. N Engl J Med 2004; 350(11): 1104-10.

[6] Ho TW, Mannix LK, Fan X, et al. Randomized controlled trial of an oral CGRP antagonist, MK-0974, in acute treatment of migraine. Neurology 2008; 70: 1304-12.

[7] Kelman L. The triggers or precipitants of the acute migraine attack. Cephalalgia 2007 ; 27(5): 394-402.

[8] Wober C, Brannath W, Schmidt K, et al. Prospective analysis of factors related to migraine attacks: the PAMINA study. Cephalalgia 2007; 27(4): 304-14.

[9] Friedman DI, De ver Dye T. Migraine and the environment Headache 2009; 49(6): 941-52.

[10] Blau JN, Solomon F. Smell and other sensory disturbances in migraine. J Neurol 1985; 232(5): 275-6.

[11] Bolay H, Rapoport A. Does low atmospheric pressure independently trigger migraine? Headache 2011; 51(9): 1426-30.

[12] Rolak LA, Brown S. Headaches and multiple sclerosis: a clinical study and review of the literature. J Neurol 1990; 237(5): 300-2.

[13] La Mantia L. Headache and multiple sclerosis: clinical and therapeutic correlations. Neurol Sci 2009; 30 (Suppl 1): S23-6.

[14] Ottman R, Lipton RB. Comorbidity of migraine and epilepsy. Neurology 1994; 44(11): 2105-10.

[15] Nilius B, Owsianik G. The transient receptor potential family of ion channels. Genome Biol 2011; 12(3): 218.

[16] Wu LJ, Sweet TB, Clapham DE. International Union of Basic and Clinical Pharmacology. LXXVI. Current progress in the mammalian TRP ion channel family. Pharmacol Rev 2010; 62(3): 381-404.

[17] Goadsby PJ, Charbit AR, Andreou AP, Akerman S, Holland PR. Neurobiology of migraine. Neuroscience 2009; 161(2): 327-41.

[18] Caterina MJ, Schumacher MA, Tominaga M, Rosen TA, Levine JD, Julius D. The capsaicin receptor: a heat-activated ion channel in the pain pathway. Nature $1997 ; 389(6653)$ : 816-24. 
[19] Tominaga M, Caterina MJ, Malmberg AB, et al. The cloned capsaicin receptor integrates multiple pain-producing stimuli. Neuron 1998; 21(3): 531-43.

[20] Szallasi A, Blumberg PM. Vanilloid (Capsaicin) receptors and mechanisms. Pharmacol Rev 1999; 51(2): 159-212.

[21] Caterina MJ, Leffler A, Malmberg AB, et al. Impaired nociception and pain sensation in mice lacking the capsaicin receptor. Science 2000; 288(5464): 306-13.

[22] Davis JB, Gray J, Gunthorpe MJ, et al. Vanilloid receptor-1 is essential for inflammatory thermal hyperalgesia. Nature 2000; 405(6783): 183-7.

[23] Christoph T, Grunweller A, Mika J, et al. Silencing of vanilloid receptor TRPV1 by RNAi reduces neuropathic and visceral pain in vivo. Biochem Biophys Res Commun 2006; 350(1): 238-43.

[24] Szallasi A, Cortright DN, Blum CA, Eid SR. The vanilloid receptor TRPV1: 10 years from channel cloning to antagonist proof-ofconcept. Nat Rev Drug Discov 2007; 6(5): 357-72.

[25] Bhave G, Zhu W, Wang H, Brasier DJ, Oxford GS, Gereau RW. cAMP-dependent protein kinase regulates desensitization of the capsaicin receptor (VR1) by direct phosphorylation. Neuron 2002; 35(4): 721-31.

[26] Bhave $\mathrm{G}, \mathrm{Hu} \mathrm{HJ}$, Glauner $\mathrm{KS}$, et al. Protein kinase C phosphorylation sensitizes but does not activate the capsaicin receptor transient receptor potential vanilloid 1 (TRPV1). Proc Natl Acad Sci U S A 2003; 100(21): 12480-5.

[27] Helliwell RJ, McLatchie LM, Clarke M, Winter J, Bevan S, McIntyre P. Capsaicin sensitivity is associated with the expression of the vanilloid (capsaicin) receptor (VR1) mRNA in adult rat sensory ganglia. Neurosci Lett 1998; 250(3): 177-80.

[28] Michael GJ, Priestley JV. Differential expression of the mRNA for the vanilloid receptor subtype 1 in cells of the adult rat dorsal root and nodose ganglia and its downregulation by axotomy. J Neurosci 1999; 19(5): 1844-54.

[29] Guo A, Vulchanova L, Wang J, Li X, Elde R. Immunocytochemical localization of the vanilloid receptor 1 (VR1): relationship to neuropeptides, the $\mathrm{P} 2 \mathrm{X} 3$ purinoceptor and IB4 binding sites. Eur J Neurosci 1999; 11(3): 946-58.

[30] Bae YC, Oh JM, Hwang SJ, Shigenaga Y, Valtschanoff JG. Expression of vanilloid receptor TRPV1 in the rat trigeminal sensory nuclei. J Comp Neurol 2004; 478(1): 62-71.

[31] Hou M, Uddman R, Tajti J, Kanje M, Edvinsson L. Capsaicin receptor immunoreactivity in the human trigeminal ganglion. Neurosci Lett 2002; 330(3): 223-6.

[32] Ichikawa H, Sugimoto T. VR1-immunoreactive primary sensory neurons in the rat trigeminal ganglion. Brain Res 2001; 890(1): 184-8.

[33] Roberts JC, Davis JB, Benham CD. [3H]Resiniferatoxin autoradiography in the CNS of wild-type and TRPV1 null mice defines TRPV1 (VR-1) protein distribution. Brain Res 2004; 995(2): 176-83.

[34] Acs G, Palkovits M, Blumberg PM. Specific binding of $[3 \mathrm{H}]$ resiniferatoxin by human and rat preoptic area, locus ceruleus, medial hypothalamus, reticular formation and ventral thalamus membrane preparations. Life Sci 1996; 59(22): 1899-908.

[35] Biro T, Toth BI, Marincsak R, Dobrosi N, Geczy T, Paus R. TRP channels as novel players in the pathogenesis and therapy of itch. Biochim Biophys Acta 2007; 1772(8): 1004-21.

[36] Biro T, Maurer M, Modarres S, et al. Characterization of functional vanilloid receptors expressed by mast cells. Blood 1998; 91(4): 1332-40.

[37] Story GM, Peier AM, Reeve AJ, et al. ANKTM1, a TRP-like channel expressed in nociceptive neurons, is activated by cold temperatures. Cell 2003; 112(6): 819-29.

[38] Bautista DM, Movahed P, Hinman A, et al. Pungent products from garlic activate the sensory ion channel TRPA1. Proc Natl Acad Sci U S A 2005; 102(34): 12248-52.

[39] Peier AM, Moqrich A, Hergarden AC, et al. A TRP channel that senses cold stimuli and menthol. Cell 2002; 108(5): 705-15.

[40] Kobayashi K, Fukuoka T, Obata K, et al. Distinct expression of TRPM8, TRPA1, and TRPV1 mRNAs in rat primary afferent neurons with adelta/c-fibers and colocalization with trk receptors. J Comp Neurol 2005; 493(4): 596-606.

[41] Okazawa M, Inoue W, Hori A, Hosokawa H, Matsumura K, Kobayashi S. Noxious heat receptors present in cold-sensory cells in rats. Neurosci Lett 2004; 359(1-2): 33-6.
[42] Shimizu T, Toriumi H, Sato H, et al. Distribution and origin of TRPV1 receptor-containing nerve fibers in the dura mater of rat. Brain Res 2007; 1173: 84-91.

[43] Evans MS, Cheng X, Jeffry JA, Disney KE, Premkumar LS. Sumatriptan Inhibits TRPV1 Channels in Trigeminal Neurons. Headache 2012; 52(5): 773-94.

[44] Akerman S, Kaube H, Goadsby PJ. Vanilloid type 1 receptors (VR1) on trigeminal sensory nerve fibres play a minor role in neurogenic dural vasodilatation, and are involved in capsaicininduced dural dilation. Br J Pharmacol 2003; 140(4): 718-24.

[45] Akerman S, Kaube H, Goadsby PJ. Anandamide acts as a vasodilator of dural blood vessels in vivo by activating TRPV1 receptors. Br J Pharmacol 2004; 142(8): 1354-60.

[46] Dux M, Santha P, Jancso G. Capsaicin-sensitive neurogenic sensory vasodilatation in the dura mater of the rat. J Physiol 2003; 552(Pt 3): 859-67.

[47] Davies AJ, North RA. Electrophysiological and morphological properties of neurons in the substantia gelatinosa of the mouse trigeminal subnucleus caudalis. Pain 2009; 146(1-2): 214-21.

[48] Han SK, Park SA, Jeon JG, et al. Functional type I vanilloid receptor expression by substantia gelatinosa neurons of trigeminal subnucleus caudalis in mice. Neurosci Lett 2009; 452(3): 228-31.

[49] Cavanaugh DJ, Chesler AT, Jackson AC, et al. Trpv1 reporter mice reveal highly restricted brain distribution and functional expression in arteriolar smooth muscle cells. J Neurosci 2011; 31(13): 506777.

[50] Vass Z, Steyger PS, Hordichok AJ, Trune DR, Jancso G, Nuttall AL. Capsaicin stimulation of the cochlea and electric stimulation of the trigeminal ganglion mediate vascular permeability in cochlear and vertebro-basilar arteries: a potential cause of inner ear dysfunction in headache. Neuroscience 2001; 103(1): 189-201.

[51] Vass Z, Dai CF, Steyger PS, Jancso G, Trune DR, Nuttall AL. Colocalization of the vanilloid capsaicin receptor and substance $\mathrm{P}$ in sensory nerve fibers innervating cochlear and vertebro-basilar arteries. Neuroscience 2004; 124(4): 919-27.

[52] Mezey E, Toth ZE, Cortright DN, et al. Distribution of mRNA for vanilloid receptor subtype 1 (VR1), and VR1-like immunoreactivity, in the central nervous system of the rat and human. Proc Natl Acad Sci U S A 2000; 97(7): 3655-60.

[53] Sasamura T, Sasaki M, Tohda C, Kuraishi Y. Existence of capsaicin-sensitive glutamatergic terminals in rat hypothalamus. Neuroreport 1998; 9(9): 2045-8.

[54] Mori F, Ribolsi M, Kusayanagi H, et al. TRPV1 channels regulate cortical excitability in humans. J Neurosci 2012; 32(3): 873-9.

[55] Chavez AE, Chiu CQ, Castillo PE. TRPV1 activation by endogenous anandamide triggers postsynaptic long-term depression in dentate gyrus. Nat Neurosci 2010; 13(12): 1511-8.

[56] Marsch R, Foeller E, Rammes G, et al. Reduced anxiety, conditioned fear, and hippocampal long-term potentiation in transient receptor potential vanilloid type 1 receptor-deficient mice. J Neurosci 2007; 27(4): 832-9.

[57] Gibson HE, Edwards JG, Page RS, Van Hook MJ, Kauer JA. TRPV1 channels mediate long-term depression at synapses on hippocampal interneurons. Neuron 2008; 57(5): 746-59.

[58] Kofalvi A, Oliveira CR, Cunha RA. Lack of evidence for functional TRPV1 vanilloid receptors in rat hippocampal nerve terminals. Neurosci Lett 2006; 403(1-2): 151-6.

[59] Benninger F, Freund TF, Hajos N. Control of excitatory synaptic transmission by capsaicin is unaltered in TRPV1 vanilloid receptor knockout mice. Neurochem Int 2008; 52(1-2): 89-94.

[60] Cavanaugh DJ, Chesler AT, Braz JM, Shah NM, Julius D, Basbaum AI. Restriction of transient receptor potential vanilloid-1 to the peptidergic subset of primary afferent neurons follows its developmental downregulation in nonpeptidergic neurons. J Neurosci 2011; 31(28): 10119-27.

[61] Eid SR. Therapeutic targeting of TRP channels--the TR(i)P to pain relief. Curr Top Med Chem 2011; 11(17): 2118-30.

[62] Moran MM, McAlexander MA, Biro T, Szallasi A. Transient receptor potential channels as therapeutic targets. Nat Rev Drug Discov 2011; 10(8): 601-20.

[63] Kissin I, Szallasi A. Therapeutic targeting of TRPV1 by resiniferatoxin, from preclinical studies to clinical trials. Curr Top Med Chem 2011; 11(17): 2159-70.

[64] Wong GY, Gavva NR. Therapeutic potential of vanilloid receptor TRPV1 agonists and antagonists as analgesics: Recent advances and setbacks. Brain Res Rev 2009; 60(1): 267-77. 
[65] Knotkova H, Pappagallo M, Szallasi A. Capsaicin (TRPV1 Agonist) therapy for pain relief: farewell or revival? Clin J Pain 2008; 24(2): 142-54.

[66] Amaya F, Oh-hashi K, Naruse Y, et al. Local inflammation increases vanilloid receptor 1 expression within distinct subgroups of DRG neurons. Brain Res 2003; 963(1-2): 190-6.

[67] Rashid MH, Inoue M, Bakoshi S, Ueda H. Increased expression of vanilloid receptor 1 on myelinated primary afferent neurons contributes to the antihyperalgesic effect of capsaicin cream in diabetic neuropathic pain in mice. J Pharmacol Exp Ther 2003; 306(2): 709-17.

[68] Pei L, Lin CY, Dai JP, Yin GF. Facial pain induces the alteration of transient receptor potential vanilloid receptor 1 expression in rat trigeminal ganglion. Neurosci Bull 2007; 23(2): 92-100.

[69] Hong S, Wiley JW. Early painful diabetic neuropathy is associated with differential changes in the expression and function of vanilloid receptor 1. J Biol Chem 2005; 280(1): 618-27.

[70] Eltorp CT, Jansen-Olesen I, Hansen AJ. Release of calcitonin generelated peptide (CGRP) from guinea pig dura mater in vitro is inhibited by sumatriptan but unaffected by nitric oxide. Cephalalgia 2000; 20(9): 838-44.

[71] Bevan S, Hothi S, Hughes G, et al. Capsazepine: a competitive antagonist of the sensory neurone excitant capsaicin. $\mathrm{Br} \mathrm{J}$ Pharmacol 1992; 107(2): 544-52.

[72] Meents JE, Neeb L, Reuter U. TRPV1 in migraine pathophysiology. Trends Mol Med 2010; 16(4): 153-9.

[73] Zhang XC, Strassman AM, Burstein R, Levy D. Sensitization and activation of intracranial meningeal nociceptors by mast cell mediators. J Pharmacol Exp Ther 2007; 322(2): 806-12.

[74] Lopshire JC, Nicol GD. The cAMP transduction cascade mediates the prostaglandin E2 enhancement of the capsaicin-elicited current in rat sensory neurons: whole-cell and single-channel studies. J Neurosci 1998; 18(16): 6081-92.

[75] Southall MD, Vasko MR. Prostaglandin receptor subtypes, EP3C and EP4, mediate the prostaglandin E2-induced cAMP production and sensitization of sensory neurons. J Biol Chem 2001; 276(19): 16083-91.

[76] Sarchielli P, Mancini ML, Floridi A, et al. Increased levels of neurotrophins are not specific for chronic migraine: evidence from primary fibromyalgia syndrome. J Pain 2007; 8(9): 737-45.

[77] Vass Z, Shore SE, Nuttall AL, Jancso G, Brechtelsbauer PB, Miller JM. Trigeminal ganglion innervation of the cochlea--a retrograde transport study. Neuroscience 1997; 79(2): 605-15.

[78] Volcy M, Sheftell FD, Tepper SJ, Rapoport AM, Bigal ME. Tinnitus in migraine: an allodynic symptom secondary to abnormal cortical functioning? Headache 2005; 45(8): 1083-7.

[79] Suri A, Szallasi A. The emerging role of TRPV1 in diabetes and obesity. Trends Pharmacol Sci 2008; 29(1): 29-36.

[80] Goadsby PJ, Edvinsson L. Human in vivo evidence for trigeminovascular activation in cluster headache. Neuropeptide changes and effects of acute attacks therapies. Brain 1994; 117( Pt 3): 427-34.

[81] Karai L, Brown DC, Mannes AJ, et al. Deletion of vanilloid receptor 1-expressing primary afferent neurons for pain control. J Clin Invest 2004; 113(9): 1344-52.

[82] Iadarola MJ, Mannes AJ. The vanilloid agonist resiniferatoxin for interventional-based pain control. Curr Top Med Chem 2011; 11(17): 2171-9.

[83] Diamond S, Freitag F, Phillips SB, Bernstein JE, Saper JR. Intranasal civamide for the acute treatment of migraine headache. Cephalalgia 2000; 20(6): 597-602.

[84] Levy RL. Intranasal capsaicin for acute abortive treatment of migraine without aura. Headache 1995; 35(5): 277.

[85] Fusco BM, Barzoi G, Agro F. Repeated intranasal capsaicin applications to treat chronic migraine. Br J Anaesth 2003; 90(6): 812 .

[86] Marks DR, Rapoport A, Padla D, et al. A double-blind placebocontrolled trial of intranasal capsaicin for cluster headache. Cephalalgia 1993; 13(2): 114-6.

[87] Fusco BM, Marabini S, Maggi CA, Fiore G, Geppetti P. Preventative effect of repeated nasal applications of capsaicin in cluster headache. Pain 1994; 59(3): 321-5.

[88] Saper JR, Klapper J, Mathew NT, Rapoport A, Phillips SB, Bernstein JE. Intranasal civamide for the treatment of episodic cluster headaches. Arch Neurol 2002; 59(6): 990-4.
[89] Rapoport AM, Bigal ME. Migraine preventive therapy: current and emerging treatment options. Neurol Sci 2005; 26(Suppl 2): s11120.

[90] Rapoport AM, Bigal ME, Tepper SJ, Sheftell FD. Intranasal medications for the treatment of migraine and cluster headache. CNS Drugs 2004; 18(10): 671-85.

[91] Cianchetti C. Capsaicin jelly against migraine pain. Int J Clin Pract 2010; 64(4): 457-9.

[92] Lambert GA, Davis JB, Appleby JM, Chizh BA, Hoskin KL, Zagami AS. The effects of the TRPV1 receptor antagonist SB705498 on trigeminovascular sensitisation and neurotransmission. Naunyn Schmiedebergs Arch Pharmacol 2009; 380(4): 311-25.

[93] Summ O, Holland PR, Akerman S, Goadsby PJ. TRPV1 receptor blockade is ineffective in different in vivo models of migraine. Cephalalgia 2011; 31(2): 172-80.

[94] Schoenen J, De KN, Giurgea S, et al. Almotriptan and its combination with aceclofenac for migraine attacks: a study of efficacy and the influence of auto-evaluated brush allodynia. Cephalalgia 2008; 28(10): 1095-105.

[95] Cady R, Martin V, Mauskop A, et al. Symptoms of cutaneous sensitivity pre-treatment and post-treatment: results from the rizatriptan TAME studies. Cephalalgia 2007; 27(9): 1055-60.

[96] Burstein R, Cutrer MF, Yarnitsky D. The development of cutaneous allodynia during a migraine attack clinical evidence for the sequential recruitment of spinal and supraspinal nociceptive neurons in migraine. Brain 2000; 123(Pt 8): 1703-9.

[97] Garcia-Anoveros J, Nagata K. TRPA1. Handb Exp Pharmacol 2007; 179: 347-62.

[98] Baraldi PG, Preti D, Materazzi S, Geppetti P. Transient receptor potential ankyrin 1 (TRPA1) channel as emerging target for novel analgesics and anti-inflammatory agents. J Med Chem 2010; 53(14): 5085-107.

[99] Bandell M, Story GM, Hwang SW, et al. Noxious cold ion channel TRPA1 is activated by pungent compounds and bradykinin. Neuron 2004; 41(6): 849-57.

[100] Macpherson LJ, Geierstanger BH, Viswanath V, et al. The pungency of garlic: activation of TRPA1 and TRPV1 in response to allicin. Curr Biol 2005; 15(10): 929-34.

[101] Jordt SE, Bautista DM, Chuang HH, et al. Mustard oils and cannabinoids excite sensory nerve fibres through the TRP channel ANKTM1. Nature 2004; 427(6971): 260-5.

[102] Zhong J, Minassi A, Prenen J, Taglialatela-Scafati O, Appendino G, Nilius B. Umbellulone modulates TRP channels. Pflugers Arch 2011; 462(6): 861-70.

[103] Nassini R, Materazzi S, Vriens J, et al. The 'headache tree' via umbellulone and TRPA1 activates the trigeminovascular system. Brain 2012; 135(Pt 2): 376-90.

[104] Bautista DM, Jordt SE, Nikai T, et al. TRPA1 mediates the inflammatory actions of environmental irritants and proalgesic agents. Cell 2006; 124(6): 1269-82.

[105] McNamara CR, Mandel-Brehm J, Bautista DM, et al. TRPA1 mediates formalin-induced pain. Proc Natl Acad Sci U S A 2007; 104(33): 13525-30.

[106] Taylor-Clark TE, Kiros F, Carr MJ, McAlexander MA. Transient receptor potential ankyrin 1 mediates toluene diisocyanate-evoked respiratory irritation. Am J Respir Cell Mol Biol 2009; 40(6): 75662.

[107] Trevisani M, Siemens J, Materazzi S, et al. 4-Hydroxynonenal, an endogenous aldehyde, causes pain and neurogenic inflammation through activation of the irritant receptor TRPA1. Proc Natl Acad Sci U S A 2007; 104(33): 13519-24.

[108] Andersson DA, Gentry C, Moss S, Bevan S. Transient receptor potential A1 is a sensory receptor for multiple products of oxidative stress. J Neurosci 2008; 28(10): 2485-94.

[109] Taylor-Clark TE, Undem BJ, MacGlashan DW, Jr., Ghatta S, Carr MJ, McAlexander MA. Prostaglandin-induced activation of nociceptive neurons via direct interaction with transient receptor potential A1 (TRPA1). Mol Pharmacol 2008; 73(2): 274-81.

[110] Wang YY, Chang RB, Liman ER. TRPA1 is a component of the nociceptive response to CO2. J Neurosci 2010; 30(39): 12958-63.

[111] Wang YY, Chang RB, Allgood SD, Silver WL, Liman ER. A TRPA1-dependent mechanism for the pungent sensation of weak acids. J Gen Physiol 2011; 137(6): 493-505.

[112] Bang S, Kim KY, Yoo S, Kim YG, Hwang SW. Transient receptor potential A1 mediates acetaldehyde-evoked pain sensation. Eur J Neurosci 2007; 26(9): 2516-23. 
[113] Matta JA, Cornett PM, Miyares RL, Abe K, Sahibzada N, Ahern GP. General anesthetics activate a nociceptive ion channel to enhance pain and inflammation. Proc Natl Acad Sci U S A 2008; 105(25): 8784-9.

[114] Diogenes A, Akopian AN, Hargreaves KM. NGF up-regulates TRPA1: implications for orofacial pain. J Dent Res 2007; 86(6): 550-5.

[115] Hinman A, Chuang HH, Bautista DM, Julius D. TRP channel activation by reversible covalent modification. Proc Natl Acad Sci U S A 2006; 103(51): 19564-8.

[116] Macpherson LJ, Dubin AE, Evans MJ, et al. Noxious compounds activate TRPA1 ion channels through covalent modification of cysteines. Nature 2007; 445(7127): 541-5.

[117] Schmidt M, Dubin AE, Petrus MJ, Earley TJ, Patapoutian A. Nociceptive signals induce trafficking of TRPA1 to the plasma membrane. Neuron 2009; 64(4): 498-509.

[118] Kwan KY, Allchorne AJ, Vollrath MA, et al. TRPA1 contributes to cold, mechanical, and chemical nociception but is not essential for hair-cell transduction. Neuron 2006; 50(2): 277-89.

[119] Corey DP, Garcia-Anoveros J, Holt JR, et al. TRPA1 is a candidate for the mechanosensitive transduction channel of vertebrate hair cells. Nature 2004; 432(7018): 723-30.

[120] Nagata K, Duggan A, Kumar G, Garcia-Anoveros J. Nociceptor and hair cell transducer properties of TRPA1, a channel for pain and hearing. J Neurosci 2005; 25(16): 4052-61.

[121] Raisinghani M, Zhong L, Jeffry JA, et al. Activation characteristics of transient receptor potential ankyrin 1 and its role in nociception. Am J Physiol Cell Physiol 2011; 301(3): C587-C600.

[122] Caspani O, Heppenstall PA. TRPA1 and cold transduction: an unresolved issue? J Gen Physiol 2009; 133(3): 245-9.

[123] Knowlton WM, Bifolck-Fisher A, Bautista DM, McKemy DD. TRPM8, but not TRPA1, is required for neural and behavioral responses to acute noxious cold temperatures and cold-mimetics in vivo. Pain 2010; 150(2): 340-50.

[124] del Camino D, Murphy S, Heiry M, et al. TRPA1 contributes to cold hypersensitivity. J Neurosci 2010; 30(45): 15165-74.

[125] Eid SR, Crown ED, Moore EL, et al. HC-030031, a TRPA1 selective antagonist, attenuates inflammatory- and neuropathyinduced mechanical hypersensitivity. Mol Pain 2008; 4: 48.

[126] Kunkler PE, Ballard CJ, Oxford GS, Hurley JH. TRPA1 receptors mediate environmental irritant-induced meningeal vasodilatation. Pain 2011; 152(1): 38-44.

[127] Bessac BF, Jordt SE. Breathtaking TRP channels: TRPA1 and TRPV1 in airway chemosensation and reflex control. Physiology (Bethesda ) 2008; 23: 360-70.

[128] Caceres AI, Brackmann M, Elia MD, et al. A sensory neuronal ion channel essential for airway inflammation and hyperreactivity in asthma. Proc Natl Acad Sci U S A 2009; 106(22): 9099-104.

[129] Bessac BF, Sivula M, von Hehn CA, Caceres AI, Escalera J, Jordt SE. Transient receptor potential ankyrin 1 antagonists block the noxious effects of toxic industrial isocyanates and tear gases. FASEB J 2009; 23(4): 1102-14.

[130] Chen J, Zhang XF, Kort ME, et al. Molecular determinants of species-specific activation or blockade of TRPA1 channels. J Neurosci 2008; 28(19): 5063-71.

[131] Macpherson LJ, Hwang SW, Miyamoto T, Dubin AE, Patapoutian A, Story GM. More than cool: promiscuous relationships of menthol and other sensory compounds. Mol Cell Neurosci 2006; 32(4): 335-43.

[132] Karashima Y, Damann N, Prenen J, et al. Bimodal action of menthol on the transient receptor potential channel TRPA1. J Neurosci 2007; 27(37): 9874-84.

[133] Everaerts W, Gees M, Alpizar YA, et al. The capsaicin receptor TRPV1 is a crucial mediator of the noxious effects of mustard oil. Curr Biol 2011; 21(4): 316-21.

[134] Petrus M, Peier AM, Bandell M, et al. A role of TRPA1 in mechanical hyperalgesia is revealed by pharmacological inhibition. Mol Pain 2007; 3: 40.

[135] Chen J, Joshi SK, DiDomenico S, et al. Selective blockade of TRPA1 channel attenuates pathological pain without altering noxious cold sensation or body temperature regulation. Pain 2011; 152(5): 1165-72.

[136] Obata K, Katsura H, Mizushima T, et al. TRPA1 induced in sensory neurons contributes to cold hyperalgesia after inflammation and nerve injury. J Clin Invest 2005; 115(9): 2393401 .
[137] Haas ET, Rowland K, Gautam M. Tooth injury increases expression of the cold sensitive TRP channel TRPA1 in trigeminal neurons. Arch Oral Biol 2011; 56(12): 1604-9.

[138] Akopian AN. Regulation of nociceptive transmission at the periphery via TRPA1-TRPV1 interactions. Curr Pharm Biotechnol 2011; 12(1): 89-94.

[139] Katsura H, Obata K, Mizushima T, et al. Antisense knock down of TRPA1, but not TRPM8, alleviates cold hyperalgesia after spinal nerve ligation in rats. Exp Neurol 2006; 200(1): 112-23.

[140] Wetsel WC. Sensing hot and cold with TRP channels. Int J Hyperthermia 2011; 27(4): 388-98.

[141] Park U, Vastani N, Guan Y, Raja SN, Koltzenburg M, Caterina MJ. TRP vanilloid 2 knock-out mice are susceptible to perinatal lethality but display normal thermal and mechanical nociception. J Neurosci 2011; 31(32): 11425-36.

[142] $\mathrm{Xu} \mathrm{H}$, Ramsey IS, Kotecha SA, et al. TRPV3 is a calciumpermeable temperature-sensitive cation channel. Nature 2002; 418(6894): 181-6.

[143] Levy D, Strassman AM. Mechanical response properties of A and $\mathrm{C}$ primary afferent neurons innervating the rat intracranial dura. $\mathrm{J}$ Neurophysiol 2002; 88(6): 3021-31.

[144] Suzuki M, Mizuno A, Kodaira K, Imai M. Impaired pressure sensation in mice lacking TRPV4. J Biol Chem 2003; 278(25): 22664-8.

[145] Wei X, Edelmayer RM, Yan J, Dussor G. Activation of TRPV4 on dural afferents produces headache-related behavior in a preclinical rat model. Cephalalgia 2011; 31(16): 1595-600.

[146] Vincent F, Duncton MA. TRPV4 agonists and antagonists. Curr Top Med Chem 2011; 11(17): 2216-26.

[147] McKemy DD, Neuhausser WM, Julius D. Identification of a cold receptor reveals a general role for TRP channels in thermosensation. Nature 2002; 416(6876): 52-8.

[148] Knowlton WM, McKemy DD. TRPM8: from cold to cancer, peppermint to pain. Curr Pharm Biotechnol 2011; 12(1): 68-77.

[149] Bautista DM, Siemens J, Glazer JM, et al. The menthol receptor TRPM8 is the principal detector of environmental cold. Nature 2007; 448(7150): 204-8.

[150] Colburn RW, Lubin ML, Stone DJ, Jr., et al. Attenuated cold sensitivity in TRPM8 null mice. Neuron 2007; 54(3): 379-86.

[151] Dhaka A, Murray AN, Mathur J, Earley TJ, Petrus MJ, Patapoutian A. TRPM8 is required for cold sensation in mice. Neuron 2007 ; 54(3): 371-8.

[152] Liu Y, Qin N. TRPM8 in health and disease: cold sensing and beyond. Adv Exp Med Biol 2011; 704: 185-208.

[153] Gauchan P, Andoh T, Kato A, Kuraishi Y. Involvement of increased expression of transient receptor potential melastatin 8 in oxaliplatin-induced cold allodynia in mice. Neurosci Lett 2009; 458(2): 93-5.

[154] Sjostrand C, Savic I, Laudon-Meyer E, Hillert L, Lodin K, Waldenlind E. Migraine and olfactory stimuli. Curr Pain Headache Rep 2010; 14(3): 244-51.

[155] Bolay H. The first phase of a migraine attack resides in the cortex. J Neural Transm 2012; 119(5): 569-74.

[156] Burstein R, Jakubowski M. Unitary hypothesis for multiple triggers of the pain and strain of migraine. J Comp Neurol 2005; 493(1): 914.

[157] Levy D, Strassman AM, Burstein R. A critical view on the role of migraine triggers in the genesis of migraine pain. Headache 2009; 49(6): 953-7.

[158] Levy D. Endogenous mechanisms underlying the activation and sensitization of meningeal nociceptors: the role of immunovascular interactions and cortical spreading depression. Curr Pain Headache Rep 2012; 16(3): 270-7.

[159] Levy D. Migraine pain and nociceptor activation--where do we stand? Headache 2010; 50(5): 909-16.

[160] Ayata C. Cortical spreading depression triggers migraine attack: pro. Headache 2010; 50(4): 725-30.

[161] Charles A. Does cortical spreading depression initiate a migraine attack? Maybe not . . Headache 2010; 50(4): 731-3.

[162] Messlinger K. Migraine: where and how does the pain originate? Exp Brain Res 2009; 196(1): 179-93.

[163] Lambert GA, Zagami AS. The mode of action of migraine triggers: a hypothesis. Headache 2009; 49(2): 253-75.

[164] Welch KM. Brain hyperexcitability: the basis for antiepileptic drugs in migraine prevention. Headache 2005; 45(Suppl 1): S2532 . 
[165] Diener HC, May A. New aspects of migraine pathophysiology: lessons learned from positron emission tomography. Curr Opin Neurol 1996; 9(3): 199-201.

[166] McGaraughty S, Chu KL, Bitner RS, et al. Capsaicin infused into the PAG affects rat tail flick responses to noxious heat and alters neuronal firing in the RVM. J Neurophysiol 2003; 90(4): 2702-10.

[167] Aurora SK, Wilkinson F. The brain is hyperexcitable in migraine. Cephalalgia 2007; 27(12): 1442-53.

[168] Bolay H, Reuter U, Dunn AK, Huang Z, Boas DA, Moskowitz MA. Intrinsic brain activity triggers trigeminal meningeal afferents in a migraine model. Nat Med 2002; 8(2): 136-42.

[169] Pietrobon D. Familial hemiplegic migraine. Neurotherapeutics 2007; 4(2): 274-84.

[170] Van Den Maagdenberg AM, Terwindt GM, Haan J, Frants RR, Ferrari MD. Genetics of headaches. Handb Clin Neurol 2011; 97: 85-97.

[171] Welch KM, D'Andrea G, Tepley N, Barkley G, Ramadan NM. The concept of migraine as a state of central neuronal hyperexcitability. Neurol Clin 1990; 8(4): 817-28

[172] Xu H, Tian W, Fu Y, Oyama TT, Anderson S, Cohen DM. Functional effects of nonsynonymous polymorphisms in the human TRPV1 gene. Am J Physiol Renal Physiol 2007; 293(6): F1865-76.

[173] Van Den Maagdenberg AM, Pietrobon D, Pizzorusso T, et al. A Cacnala knockin migraine mouse model with increased susceptibility to cortical spreading depression. Neuron 2004; 41(5): 701-10.

[174] Eikermann-Haerter K, Dilekoz E, Kudo C, et al. Genetic and hormonal factors modulate spreading depression and transient hemiparesis in mouse models of familial hemiplegic migraine type 1. J Clin Invest 2009; 119(1): 99-109.

[175] Eikermann-Haerter K, Yuzawa I, Qin T, et al. Enhanced subcortical spreading depression in familial hemiplegic migraine type 1 mutant mice. J Neurosci 2011; 31(15): 5755-63.

[176] Moskowitz MA. Neurogenic inflammation in the pathophysiology and treatment of migraine. [Review] [43 refs]. Neurology 1993; 43(6 Suppl 3): S16-20.

[177] Zhang X, Levy D, Kainz V, Noseda R, Jakubowski M, Burstein R. Activation of central trigeminovascular neurons by cortical spreading depression. Ann Neurol 2011; 69(5): 855-65.

[178] Zhang X, Levy D, Noseda R, Kainz V, Jakubowski M, Burstein R. Activation of meningeal nociceptors by cortical spreading depression: implications for migraine with aura. J Neurosci 2010; 30(26): 8807-14.

[179] Levy D, Burstein R, Kainz V, Jakubowski M, Strassman AM. Mast cell degranulation activates a pain pathway underlying migraine headache. Pain 2007; 130(1-2): 166-76.

[180] Levy D. Migraine pain, meningeal inflammation, and mast cells. Curr Pain Headache Rep 2009; 13(3): 237-40.

[181] Goadsby PJ, Edvinsson L. The trigeminovascular system and migraine: studies characterizing cerebrovascular and neuropeptide changes seen in humans and cats. Annal Neurol 1993; 33(1): 48-56.

[182] Sarchielli P, Alberti A, Baldi A, et al. Proinflammatory cytokines, adhesion molecules, and lymphocyte integrin expression in the internal jugular blood of migraine patients without aura assessed ictally. Headache $2006 ; 46(2): 200-7$.

[183] Theoharides TC, Donelan J, Kandere-Grzybowska K, Konstantinidou A. The role of mast cells in migraine pathophysiology. Brain Res Brain Res Rev 2005; 49(1): 65-76.

[184] de Vries B., Frants RR, Ferrari MD, Van Den Maagdenberg AM. Molecular genetics of migraine. Hum Genet 2009; 126(1): 115-32.

[185] Ophoff RA, Terwindt GM, Vergouwe MN, et al. Familial hemiplegic migraine and episodic ataxia type- 2 are caused by mutations in the Ca2+ channel gene CACNL1A4. Cell 1996; 87(3): 543-52.

[186] De Fusco M, Marconi R, Silvestri L, et al. Haploinsufficiency of ATP1A2 encoding the $\mathrm{Na}+\mathrm{K}+$ pump alpha2 subunit associated with familial hemiplegic migraine type 2. Nat Genet 2003; 33(2): 192-6.

[187] Dichgans M, Freilinger T, Eckstein G, et al. Mutation in the neuronal voltage-gated sodium channel SCN1A in familial hemiplegic migraine. Lancet 2005; 366(9483): 371-7.

[188] Lafreniere RG, Cader MZ, Poulin JF, et al. A dominant-negative mutation in the TRESK potassium channel is linked to familial migraine with aura. Nat Med 2010; 16(10): 1157-60.

[189] Chasman DI, Schurks M, Anttila V, et al. Genome-wide association study reveals three susceptibility loci for common migraine in the general population. Nat Genet 2011;43(7): 695-8.

[190] Kremeyer B, Lopera F, Cox JJ, et al. A gain-of-function mutation in TRPA1 causes familial episodic pain syndrome. Neuron 2010; 66(5): 671-80.

[191] Aamodt AH, Stovner LJ, Hagen K, Brathen G, Zwart J. Headache prevalence related to smoking and alcohol use. The Head-HUNT Study. Eur J Neurol 2006; 13(11): 1233-8.

[192] Trevisani M, Smart D, Gunthorpe MJ, et al. Ethanol elicits and potentiates nociceptor responses via the vanilloid receptor-1. Nat Neurosci 2002; 5(6): 546-51

[193] Nicoletti P, Trevisani M, Manconi M, et al. Ethanol causes neurogenic vasodilation by TRPV1 activation and CGRP release in the trigeminovascular system of the guinea pig. Cephalalgia 2008; 28(1): 9-17.

[194] Panconesi A. Alcohol and migraine: trigger factor, consumption, mechanisms. A review. J Headache Pain 2008; 9(1): 19-27.

[195] Pall ML, Anderson JH. The vanilloid receptor as a putative target of diverse chemicals in multiple chemical sensitivity. Arch Environ Health 2004; 59(7): 363-75.

[196] Cullen MR. The worker with multiple chemical sensitivities: an overview. Occup Med 1987; 2(4): 655-61.

[197] Kimata H. Effect of exposure to volatile organic compounds on plasma levels of neuropeptides, nerve growth factor and histamine in patients with self-reported multiple chemical sensitivity. Int $\mathrm{J}$ Hyg Environ Health 2004; 207(2): 159-63.

[198] Ternesten-Hasseus E, Bende M, Millqvist E. Increased capsaicin cough sensitivity in patients with multiple chemical sensitivity. J Occup Environ Med 2002; 44(11): 1012-7.

[199] Meggs WJ. Neurogenic inflammation and sensitivity to environmental chemicals. Environ Health Perspect 1993; 101(3): 234-8.

[200] Andre E, Campi B, Materazzi S, et al. Cigarette smoke-induced neurogenic inflammation is mediated by alpha,beta-unsaturated aldehydes and the TRPA1 receptor in rodents. J Clin Invest 2008; 118(7): 2574-82

[201] Benemei S, Appendino G, Geppetti P. Pleasant natural scent with unpleasant effects: cluster headache-like attacks triggered by Umbellularia californica. Cephalalgia 2010; 30(6): 744-6.

[202] Doganay H, Akcali D, Goktas T, et al. African dust-laden atmospheric conditions activate the trigeminovascular system. Cephalalgia 2009; 29(10): 1059-68.

[203] Shi R, Rickett T, Sun W. Acrolein-mediated injury in nervous system trauma and diseases. Mol Nutr Food Res 2011; 55(9): 132031 .

[204] Theeler BJ, Erickson JC. Mild head trauma and chronic headaches in returning US soldiers. Headache 2009; 49(4): 529-34. 